\title{
DESIGNING CANCER GROUPS FOR MAXIMUM EFFECTIVENESS
}

\section{BARRY M. DASTE}

This article attempts to shed light on some of the problems involved in developing optimum service groups for cancer patients and offers ideas concerning the design, content, leadership and membership of these groups. The article begins with a literature review of current research on issues faced by cancer patients and how these have been handled in support groups and therapy groups across the country. Following this, suggestions are offered to assist those involved in planning for these groups to deal with some of the potential difficulties encountered by many of these groups. Interest in this project grew out of the author's personal experience with cancer and from the experience of being first a participant, and later a leader, in groups for cancer patients.

While a review of various types of groups for cancer patients reveals some very interesting and apparently quite successful efforts, there appears to be a lack of general agreement regarding the purpose of these groups and how they might best be developed. This article attempts to shed light on some of the problems involved in developing optimum service groups for cancer patients and offers ideas concerning the design, content, leadership and membership of these groups. The article begins with a look at issues faced by cancer patients and how these have been handled in support groups and therapy groups across the country. Following this, proposed suggestions are offered which might help those involved in planning for these groups to anticipate, and thus be in a position to circumvent, some of the potential difficulties. Interest in this project grew out of the author's personal experience with cancer and from the experience of being first a participant, and later a leader, in groups for cancer patients.

\section{Review of some important findings}

Of the groups currently in existence serving cancer patients, many are mutual support groups or self-help groups. In a recent article, Lieberman [1988] reviewed the benefits and limitations of self-help groups formed around a number of different problems, including cancer 
self-help groups. He also compared these groups with groups led by professionals. Lieberman reported that fewer studies have been performed on self-help groups and that conclusions regarding their efficacy are not definite. However, he summarized the article by stating that both types of groups appear to have 'meaningfuL roles in helping individuals with psychosocial problems' (P. 168).

Professionally led groups go by various names, and they differ in their emphases, in their membership requirements, in number of sessions, in type of leadership, and in other areas as well. Some offer a combination of services, including support, education, and therapy. A number have been subjects of research [Ferlic et al., 1979; Taylor et al., 1986; Telch and Telch, 1986; Spiegel and Bloom, 1983; Yalom and Greaves, 1977] and will be discussed in this article. The general conclusions of these studies have been positive regarding the advantages obtained by members in several important areas.

In their work with women with metastatic carcinoma of the breast, Yalom and Greaves [1977] report the group format to be 'an exceptionally effective therapeutic model' [p. 399]. This group is referred to as both a therapy and a support group in various articles [Spiegel and Yalom, 1978; Yalom and Greaves, 1977]. Spiegel and Yalom [1978] state that it is not a psychotherapy grop although 'there is pressure by members to do psychotherapy at times' [p. 241]. They point out that the characterological issues which a psychotherapist would address become secondary to the life choices called for in a situation of terminal illness.

Berger [1984], in describing a drop-in support group which utilizes a crisis intervention model for both patients and families, asserts that people do not attend the group for psychotherapy. Yet she goes on to say that they are seeking 'answers regarding their illness which in turn leads to a recognition of their feelings and relief from feeling guilty for having such feelings' [p. 83]. If characterological issues and problems of guilt, anger, and fear are being brought to the group, then psychotherapy certainly seems appropriate, even if those issues are secondary to other pressing concerns. These issues are significant to quality of life and may warrant greater intervention than mutual support or self-help models alone can offer.

The kinds of problems that accompany the crises in the life of a cancer patient vary according to the type of cancer and the stage of the illness. There is variance as well, according to the particular situation of each person, for example, the age when cancer is discovered and the quality and extent of the person's resources and support. However, there are a number of psychological issues which arise to some degree in all cases and which can be addressed in groups designed to offer therapy 
through intensive systematic intervention. Some of these issues are outlined below.

\section{Psychosocial issues common to cancer patients}

\section{SELF-IMAGE}

The issues of self-image and self-esteem are critical for cancer patients. One's image as a healthy functional person with a certain role in society and a certain amount of control over one's life is now called into question. These changes in self-image, as well as those physical changes which threaten a person's self-esteem, can be addressed in a therapy group. Ferlic, Goldman and Kennedy [1978] reported a significant increase in self concept in 30 oncology patients through group counseling sessions, which included patient education and discussion on such topics as nutrition, physical activity, religion, and sexuality and the cancer patient. In the women's group described earlier, patients reported improvement in communication with families and doctors, growth in assertiveness, and a new 'sense of importance and... meaning in their lives' (Spiegel and Yalom, 1978, p. 244).

\section{ANXIETY, ANGER, AND DEPRESSION}

Anxiety, anger, and depression are prominent issues, arising from a number of sources. In terminally ill patients, the fear of death and the loneliness and isolation that may accompany dying are paramount. In a later evaluation of the on-going women's group, Spiegel (1986, p. 89) states:

... death anxiety was addressed directly ... Patients found that they could divide their anxiety about dying into specific concerns such as pain, loss of control, and separation from loved ones and friends, which seemed to be more manageable. Group members encouraged one another to be assertive and to recognize and express their anger in appropriate ways. They provided one another with role models of controlled expressions of anger, thereby developing a sense of mastery and acceptance.

Spiegel and Yalom [1978] report a lessening of depression in the group.

Smith and Lesko [1988] cite major causes of anxiety in cancer survivors: uncertainty about the future, intrusion of the past traumatic aspects of dealing with cancer; persistence of pain and other physical symptoms; and re-entry problems (going back to school or work, resuming relationships). Reasons for frustration and anger at physicians 
are indicated in several studies [van Brunschot et al., 1984; Maguire et al., 1976; Sie, 1980, cited in Cuisinier et al., 1986]. Patients often reported that their physicians showed a lack of understanding of their psychosocial needs as well as providing an unsatisfactory degree of education about the disease. Regarding a group of patients and families, Wellisch, Mosher and Van Scoy [1978, p. 229] write that:

dealing with anger toward physicians is a task of the group ... the group is a safe arena for the expression of powerful emotions such as fear, rage and sadness ... the group reinforces the notion that patients and family members are persons of equal stature with the physicians and will not face revenge (psychologically experienced as fears of lack of treatment) if honest emotions are expressed toward them.

Regarding the need for information, Mumford, Schlesinger and Glass (1982, cited in Cuisinier et al., 1986) show that well-informed patients are often in better condition than those who are uninformed. They found that 'well-informed patients experienced less pain and that fewer complications occur in the disease process' [p. 10].

In a study of patients with Hodgkins disease by Jacobs, Rose, Walker and Stockdale [1983, cited in Cuisinier et al., p. 10.]:

... it is shown that following education patients experienced significant decrease in the frequency of anxiety, depression, negative effects of chemotherapeutic treatment and feelings of life disruption.

Telch and Telch [1986] used an intervention of instruction in coping skills with a group for cancer patients. They report that patients 'regained a sense of personal control and mastery by learning techniques for coping with stressful thoughts, feelings, and behaviours' [p. 807]. These studies speak strongly for an education component either within the therapy group or as an adjunct, including not only teaching about aspects of cancer but also assertiveness skills and other coping and communication skills.

\section{Fear of loss of support}

A major problem for cancer patients which was alluded to earlier is fear of loss of social support. Rickert and Koffman [1982] write about the fear of abandonment which occurs when a person becomes increasingly dependent on a smaller support system, usually the family. They point 
out that family and other loved ones do sometimes withdraw to preserve their own comfort.

Unless families and friends are able to communicate in a helpful way about the most important things going on between them, frustration and a subtle mutual alienation may occur, and the patient feels abandoned [p. 33].

Smith and Lesko cite Wortman and Dunkel-Schletter [1979] in regard to reactions to cancer patients which take place during the treatment phase and even into the survival period. They say a fear of catching cancer and a feeling of disgust about the disease lead to avoidance of the patient, an avoidance of the topic of cancer, illness, and death, and unpredictable behavior due to ambivalent feelings towards the patient.

Cancer patients often worry about being a burden to family and friends and even fear 'losing the support of spouse, friends, or physicians if they complain too much about their emotional state' [Cohen, 1988, p. 41, in a review of Smith and Lesko, 1988]. Returning once more to the groupwork among women with metastatic breast cancer, Yalom and Greaves [1977] state:

In this group as in all therapy groups one becomes ever more cognizant of the overarching need people have for other people. The group spends much time and does much effective work with patients who, because of characterological style or particular methods of coping with recent stress have cut themselves off from others [p. 398].

Simply being part of a group helped relieve some feelings of isolation and loneliness, but further, it gave members tools for better communication with other significant persons in their lives.

\section{REACTIONS OF DENIAL, GRIEF AND GUILT}

Finally, in the face of overwhelming psychological, social, and physical stress, reactions of denial, grief and guilt are common. Whitman, Gustafson, and Coleman [1979] discuss defenses that group members employ to avoid difficult issues. They suggest that the therapist's role is to move the group off safe superficial subjects to more troubling questions such as death and suicide. However, it is important for clinicians to understand with some specificity the nature of the patient's denial so as to ascertain its potential adaptive or maladaptive effects [Wool and Goldberg, 1986]. Hyland, Pruyser, Navotny and Coyne 
[1984] warn that denial can be used maladaptively by both patients and counselors. The issue of denial and other difficult issues such as grief over losses of physical and social gratification [Kelly and Ashby, 1979] and guilt, mentioned earlier in a quotation from Berger [1984], can be handled most effectively when the help of experienced and well trained group leaders is available.

\section{Structuring the optimal group}

Clearly, groups for cancer patients are quite diverse and do not adhere to unified interventions. There does not seem to be a clear delineation between support groups and therapy groups. Some groups are open to patients only [Ferlic et al., 1979] while other groups include family members [Wellisch et al., 1978; Berger, 1984]. Additionally, several studies offer excellent ideas regarding an education component, including such topical content as nutrition, religion, and sexuality. While diversity and variety in group design undoubtedly will and should remain, it is important to raise questions about maximizing the effectiveness of these groups by addressing issues of structure and formation.

Having reviewed the complex issues of cancer patients and some of the various ways they have been handled in professionally-led groups, this article now focuses on suggestions for organizing and structuring effective groups by examining the questions of design, content, leadership, and membership.

\section{DESIGN}

The optimally designed group might well be an open group which stresses attendance but does not demand it to the extent that many psychotherapy groups do. Resistance in the form of missed sessions should be addressed. Leaders need to be particularly sensitive to the fact that people will often miss sessions because they do not want to deal with painful feelings. It is important to realize, however, that due to the nature of the illness, persons are often too ill to attend. This is particularly true of those persons who are recovering from surgery, those persons in later stages of the disease, as well as those who are experiencing side effects from chemotherapy and/or radiation. With these possible exceptions in mind, it might be important for leaders to point out that while it may be difficult for members to express painful feelings and it may be easier for them to stay away from the group, the benefits to be gained from attending and expressing these feelings may far outweigh the advantages of staying away.

The size of the group should also be given careful consideration. 
Many support groups are so large that persons do not have an opportunity to participate as fully as they might. To maximise participation, groups should probably be started with no more than 10-12 members. To allow for early attrition, one should probably begin with at least 5-6 members. As time goes on and the size decreases to a low of 3-4 members, new members should be added. An optimum size of around seven members, as occurs in many therapy groups, would seem to be ideal. There needs to be some degree of flexibility in this, however, again due to the nature of the illness.

Another factor to be considered in regard to design is the need for a crisis intervention approach on a need basis. While member crises occur in all therapy groups from time to time, cancer patients frequently have severe crises due to recurrences, and other changes which can come up quite suddenly. The group must be prepared to put aside other concerns and help members who are undergoing the crisis. Stabilisation may take several sessions as usually occurs in crisis intervention situations.

While the group should always offer support, it should not be solely support oriented. Members frequently have a great deal of anger, fear, and other emotions which need to be addressed. The groups cannot be strictly therapy oriented either. For example, using such concepts as the recapitulation of past events in member interaction would not receive as much focus in cancer groups as they might in other psychotherapy groups.

It seems to the author that having a more psychotherapeutic focus as opposed to a purely support focus addresses more needs of the patients. This approach, however, requires carefully selected, trained, and experienced group therapists. The forthcoming section on leadership addresses this point in more detail.

\section{CONTENT}

Content is perhaps all too often determined solely by questions which are raised by the members of a group. It is important for leaders to offer suggestions for content and then to solicit feedback from the members regarding what should be addressed, and when it should be addressed. The members should have the final decision on what content is covered. There are many important issues which face cancer patients that are not always brought up in groups. These issues occur in varying degrees, however, and are important topics for group leaders to be aware of and to help the group pursue. Studies mentioned earlier indicated the value and importance of pursuing a number of topics.

The benefit of having an educational component in these groups 
cannot be over emphasised. Many of the articles reviewed report very positive experiences with educational components. Having an educational component does not, however, preclude doing therapy in these groups. It serves to broaden the experience and to offer many answers to questions of vital importance to the members. The educational component also serves to attract members who are often reluctant to attend groups that deal more exclusively with feelings. Based on the experience of several authors and group leaders, content which should probably be addressed in all groups include the topics of nutrition, sexuality, quality of resources (family, friends, etc.), anger (at various objects including physicians and other medical personnel), fear of loneliness and isolation, pain, loss of control of bodily functions, fear of rejection, loss of support from loved ones, and fear of death. There are also other more obvious areas such as the management of side effects of treatment and some not so obvious areas such as disfigurement and grief over the loss of physical and social gratification, which should also be dealt with as the need arises.

Finally, it is important that groups be prepared to include content in such mastery techniques as stress reduction, relaxation training, desensitisation, assertiveness training, self-hypnosis, thought stopping, etc.

\section{LEADERSHIP}

Leaders of groups for cancer patients should be carefully trained, highly motivated individuals, who have a strong interest in working with cancer patients. These groups, properly designed, can be very rewarding yet they can also be tremendously taxing. Leaders should be prepared to learn techniques such as relaxation training, self-hypnosis, assertiveness training, etc. They must be prepared to deal with issues surrounding death and suicide: many avoid this topic, at times in an attempt to protect the patient, and at times in an effort to protect themselves. Leaders must consider carefully the range of their own denial patterns as well as those of the patients.

Leaders should be prepared to learn and teach the mastery techniques mentioned earlier. However, it may be neither necessary nor possible for leaders to be competent in all of the significant topical areas. At times it may be more helpful and practical to bring in persons with expertise in areas such as nutrition, chemotherapy, and radiation. It is important, though, to prepare the group for these 'outside experts' and to take steps to ensure that confidentiality and self-disclosure are safeguarded. 
Uniform training for leaders is difficult due to the diversity of settings and the diversity of prospective workers. Leaders should be professionally qualified with a sound background in groupwork. They should also be taught additional skills by persons with strong oncology backgrounds and by those with expertise in various other specific areas, e.g. death and dying, relaxation, nutrition etc. It is also very important that leaders have consultation readily available in a number of key areas, such as group leadership, general oncology, and the effects of surgery, radiation and chemotherapy.

Ideally, perhaps, leaders might have personal experiences with cancer. Going through such experiences as surgery, radiation, and chemotherapy, or having a loved one experience them, undeniably gives a leader greater insight into the unique situations in which cancer patients find themselves. This can be problematic as well, however, in that painful personal issues and fears can be rekindled in the leader who has had personal cancer experience. The author, having undergone surgery, radiation, and chemotherapy, feels that these events contributed substantially to his understanding of many of the issues faced by cancer patients. It also undeniably contributed to members' acceptance of him as a group leader. The leader must be prepared to deal with these issues and preferably would have already completed his/her treatments, and thus be somewhat temporally removed from the actual experiences.

Another valuable experience for the author was having the opportunity to attend support groups during a critical phase of his treatment, prior to forming and leading a group. As is the case with leading therapy groups, having prior 'member' experience can be quite valuable, because the individual can then relate from personal experience to the typical member issues and anxieties. The author's experience while being a member provided valuable insight, not only into what some of the members think and feel, but also into the weaknesses and structural problems inherent in many such groups.

\section{MEMBERSHIP AND COMPOSITION}

The members of cancer patient groups can be selected in a number of ways. Many groups are formed on the basis of type or bodily location of the cancer, while others are left open to all patients regardless of the type or location of the cancer. There are advantages to having groups which deal with specific types and locations of cancer in that there are certain specific secondary physical and/or psychological difficulties which occur with certain populations (such as groups for those who have lost bodily functions, mastectomy groups, etc.). Much of the 
decision, however, is governed by the size of the population served by a given treatment facility. Groups can also be formed around other issues such as stage of the disease, age of the patient, adjuvant versus nonadjuvant chemotherapy patients, etc.

It has been the author's experience, however, that although it is helpful in some ways to organise groups around specific criteria, the overriding issue of the experience of cancer itself is a far more important unifying factor than the heterogeneity/homogeneity issues related to types, locations, stage, etc.

Another issue which frequently arises is whether groups should be for patients only, or whether they should include family members and other loved ones. Groups throughout the world are designed both ways. Having led both types of groups, the author's conclusions are that there are advantages and disadvantages to both types. 'Patient only' groups allow for more expression of negative feelings toward significant others, more discussion of topics such as sexuality and fear of death, etc. On the other hand, family and friends plus patient groups can offer the potential for deeper understanding of support issues, the opportunity for dealing with feelings regarding significant others, etc.

Some issues which need to be thought out in deciding who should be included in the groups are as follows:

i. Does including significant others help or hinder the patient?

ii. Do all patients have significant others who will attend? If not, then it may be more appropriate to have a group solely composed of those who do not have significant others.

iii. How large can the group be to allow realistically for full participation?

iv. Who should be included among the significant others? For example, if sexuality is discussed does one want ones' parents and/or children in the group, as well as ones' spouse or lover?

These are quite sensitive areas and should be considered prior to forming the group.

The author at present includes all who want to attend, but reserves the right to limit the attendance when it appears that:

i. the size becomes cumbersome;

ii. sensitive issues such as sexuality require discussion.

In either case, he will simply announce that a special session will be for patients only, for patients and spouses, lovers, etc. This approach seems to work quite well. 
As mentioned earlier, the size of the group should be kept manageable and members should be encouraged to attend regularly as much as possible. It is difficult to maintain a steady attendance pattern in these groups. It is therefore essential that the attendance issue be addressed each session by having a system to predict attendance (such as calling members the day before a session is scheduled) and if necessary breaking up into separate groups when the size becomes too large.

\section{Conclusion}

While a great deal of good is currently being accomplished in cancer groups throughout the world, there remains a need for more careful planning in this area. Hopefully, the foregoing discussion of the issues involved and the suggestions for future groups will be useful to all of us who are engaged in the pursuit of the best possible services. This is a fruitful area for further research. Many persons with very pressing needs can only stand to benefit from studies which seek to improve the quality of service.

\section{Acknowledgement}

Special credit is given to Diana D'Avy, MSW and Richard Babin, MSW for their assistance in the preparation of this manuscript.

\section{References}

Berger, J. (1984) 'Crisis intervention: A drop-in support group for cancer patients and their families', Social Work in Health Care, 10 (2).

Brunschot, C. van, Verbunt, H., Pruyn, J. and Borne, H. van den (1984) 'De Huisarts in de Begeleiding van Kankerpatienten', Rapport. Tilburg, Instituut voor Sociaal-wetenschappelijk onderzoek (IVA).

Cohen, J. (1988) The article (Smith and Lesko) reviewed, Oncology, 2 (1).

Cuisinier, M.C.J., Van Erijk, J. Th. M., Jonkers, R. and Dokter, H.J. (1986) 'Psychosocial care and education of the cancer patient: Strengthening the physician's role', Patient education and counseling, 8.

Ferlic, M., Goldman, A. and Kennedy, B.J. (1979) 'Group counseling with adult patients with advanced cancer', Cancer, 43.

Hyland, J.M., Pruyser, H., Navotny, E. and Coyne, L. (1984) 'The impact of the death of a group member in a group of breast cancer patients', American Journal of Group Psychotherapy, 34 (4).

Kelly, P.P. and Ashby, G.C. (1979) 'Establishing a group,' American fournal of Nursing, May.

Lieberman, M.A. (1988) 'The role of self-help groups in helping patients and families cope with cancer', Ca-A Cancer fournal for Clinicians 38 (3). 
Maguire, P., Rutter, D. and Bennett, A.E. (1976) Communication between Doctors and Patients. Oxford: University Press.

Rickert, M.L. and Koffman, A. (1982) in M. Seligman (ed.), Group Psychotherapy and Counseling in Special Populations. Baltimore: University Park Press, pp. 27-42.

Sie, H.B. (1980) Het zit In't Bloed, Doctoraal Scriptie. Universiteit van Amsterdam.

Smith, K. and Lesko, L.M. (1988) 'Psychosocial problems in cancer survivors', Oncology, January.

Spiegel, D. (1986) 'Psychosocial interventions with cancer patients', fournal of Psychosocial Oncology, 3 (4).

Spiegel, D. and Bloom, J.R. (1983) 'Group therapy and hypnosis reduce metastatic breast carcinoma pain', Psychosomatic Medicine, 45 (4).

Spiegel, D. and Yalom, I.D. (1978) 'A support group for dying patients', International fournal of Group Psychotherapy, 28 (2).

Taylor, S.E., Falke, R.L., Shoptaw S.J. and Lichtman, R.R. (1986) 'Social support, support groups, and the cancer patient', fournal of Consulting and Clinical Psychology, 54 (5).

Telch, C.F. and Telch, M.J. (1986) 'Group coping skills instruction and supportive group therapy for cancer patients: A comparison of strategies', fournal of Consulting and Clinical Psychology, 54 (6).

Wellisch, D.K., Mosher, M.B. and Van Scoy, C. (1978) 'Management of family emotion stress: Family group therapy in a private oncology practice', International Journal of Group Psychotherapy, 28 (2).

Whitman, H.H., Gustafson, J.P. and Coleman, F.W. (1979) 'Group approaches for cancer patients: Leaders and members', American fournal of Nursing, May.

Wool, M.S. and Goldberg, R.J. (1986) 'Assessment of denial in cancer patients: Implications for intervention', Gournal of Psychosocial Oncology, 4 (3).

Yalom, I.D. and Greaves, C. (1977) 'Group therapy with the terminally ill', American fournal of Psychiatry, 134 (4). 